\title{
Early prediction of severity of necrotizing enterocolitis in preterm infants: A composite scoring tool
}

\author{
Cecilia U Grino ${ }^{1}$, Malki Miller², Vivian Carrasquilla-Lopez ${ }^{1,2}$, Mary Rojas ${ }^{3}$, Alok Bhutada ${ }^{2}$, Shantanu Rastogi*2 \\ ${ }^{1}$ Department of Nursing, Maimonides Medical Center, United States \\ ${ }^{2}$ Division of Neonatology, Department of Pediatrics, Maimonides Medical Center, United States \\ ${ }^{3}$ Division of Pediatric Research, Department of Pediatrics, Maimonides Medical Center, United States
}

Received: January 23, 2016

Accepted: May 19, 2016

Online Published: June 12, 2016

DOI: $10.5430 / \mathrm{cns} . v 4 \mathrm{n} 3 \mathrm{p} 47$

URL: http://dx.doi.org/10.5430/cns.v4n3p47

\begin{abstract}
Background: Necrotizing enterocolitis (NEC) predominantly affects preterm infants and is associated with high mortality and morbidity. There is no composite scoring tool that predicts the severity of NEC in preterm infants early in the disease process before it is established.

Methods: A retrospective chart review was performed on NEC cases $(n=41)$ defined as infants who developed NEC stage $\geq 2$ with pneumatosis intestinalis, and controls $(n=41)$ defined as infants with NEC stage 1 , to develop a scoring tool that utilized the preterm infant's clinical status, feeding practices, radiographic and laboratory findings at set time-points ( 7 days, 2 days and 24 and 12 hours) before the suspicion of NEC to predict the severity of NEC. Repeated measures analysis along with sensitivity, specificity and area under curve were measured to compare the composite risk score between cases and controls.

Results: The composite risk score was higher among the cases at 24 hours $(2.73 \pm 0.20$ vs. $2.20 \pm 0.20, p<.05)$ and 12 hours ( $4.20 \pm 0.22$ vs. $2.50 \pm 0.22, p<.001)$ but not on 2 day ( $2.37 \pm 0.17$ vs. $2.18 \pm 0.17, p=.42$ ) prior to the suspicion of NEC to predict the severity of the disease. Feeding practices, gastric residuals, and laboratory signs of inflammation were main determinants of the final score. The most discriminatory score to differentiate between NEC stage 1 and NEC stage 2 and 3 was $\leq 2$.

Conclusions: This scoring system is easy to use as it utilizes normally collected data and can predict the severity of the disease enabling the physician to make decisions regarding appropriate timing of correct treatment. Further larger prospective studies are required to validate this pilot study describing NEC severity prediction tool.
\end{abstract}

Key Words: Preterm infants, Necrotizing enterocolitis, Scoring tool, Prediction tool, Area under curve

\section{INTRODUCTION}

Necrotizing enterocolitis (NEC) predominantly affects preterm infants and is associated with high mortality and morbidity despite advances in neonatal care. ${ }^{[1]}$ NEC affects up to $5 \%$ of infants hospitalized in the NICU and of those affected, more than $90 \%$ are preterm. ${ }^{[1-3]}$ Fatality rates for NEC can approach $50 \%$ for infants requiring surgical management and is even higher for the extreme preterm infants. ${ }^{[1,3,4]}$ Further, survivors of NEC are likely to suffer poor growth, and gastrointestinal, and neurodevelopmental sequelae because of the complications related to NEC. ${ }^{[5,6]}$

The uncertainty and the rapidity of disease progression in NEC and its poor prognosis warrants a tool that could help predict the severity of NEC in its early stages. More recent

\footnotetext{
*Correspondence: Shantanu Rastogi; Email: srastogi@maimonidesmed.org; Address: Albert Einstein College of Medicine, Maimonides Infants and Children's Hospital, 4802 Tenth Ave, K113, Brooklyn NY 11219, United States.
} 
studies looking for early biomarkers of gut injury, necrosis or inflammation, such as fatty acid binding protein, fecal calprotectin, selected urine proteins associated with intestinal pathology, and platelet activating factor, are promising. ${ }^{\text {[-11] }}$ However, these tests are invasive, costly, and not done as part of routine care.

Thus, several studies attempted to identify risk factors associated with NEC and to develop scoring tools that may predict the risk of NEC which use either a single clinical or laboratory parameter or a combination at the time of birth or early after birth. ${ }^{[12-15]}$ Gephart et al. developed GutCheck, a tool used to predict the occurrence of NEC based on evaluating several known risk factors, including gestational age (GA), history of blood transfusions, sepsis, metabolic acidosis and human milk feeding. ${ }^{[12]}$ Similarly, McKeown et al. identified clinical parameters such as respiratory changes immediately preceding a diagnosis of NEC. ${ }^{[15]}$ However, these tools do not include a composite of clinical, laboratory or radiological parameters in their scoring system that are temporally related to the time before NEC is suspected, as the purpose for these tools was for prediction of occurrence of NEC, rather than the predicting of disease severity. Early prediction of NEC severity would allow early aggressive management of at-risk infants by withholding feeds and initiation of broad-spectrum antibiotics. It would also prevent indiscriminate use of antibiotics in all cases of suspected NEC, particularly in light of the recent literature linking poor neonatal health outcomes with prolonged length of stay in the hospital and concomitant increased cost of care with altered microbiome due to use of antibiotics. ${ }^{[16,17]}$

More recently, Sho et al. ${ }^{[18]}$ created a scoring system to predict the progression of NEC stage 2 to NEC-totalis, involving intestinal necrosis associated with universal mortality, based on clinical data at time of diagnosis of NEC, including low platelets, high creatinine, and high phosphorus. While this tool predicts the progression of NEC stage 2 to NEC-totalis, there is a paucity of studies that utilize readily available bedside data that can differentiate NEC stage 2 and 3 from NEC stage 1 of NEC early in the disease course. Fox et al. ${ }^{[19]}$ attempted to developed a scoring tool used to predict progression to NEC stage 1 with early intervention leading to cessation of progression to NEC stage 2-3. The parameters used were readily available clinical data, including behavioral, cardiovascular, respiratory and gastrointestinal parameters, but lacked inclusion of routine laboratory and radiological data. In this study babies were assessed for NEC stage 1 where aggressive intervention prevented the disease to progress to Stage 2 and 3.

There is a time period between the clinical suspicion of
NEC and its definitive diagnosis, particularly when the disease is of clinical stage $\geq 2$. However, there is no specific etiologic or clinical factor can accurately predict the progression of NEC with high sensitivity and specificity, therefore, development of a tool or clinical score to facilitate early prediction of severity of NEC could lead to rapid initiation of antibiotics and withholding of enteral feeds, which may stop or ameliorate the disease process and improve disease outcomes and can prevent indiscriminate use of antibiotics in this vulnerable patients. Further, as newer biomarkers are being developed they can be used appropriately to confirm the diagnosis and use of newer therapies could be used in a cost effective manner Therefore, the aim of the study was to develop a scoring tool utilizing common bedside clinical, radiographic, laboratory, feeding parameters and details of gastric residuals that will allow early prediction of progression of disease severity among patients with NEC, which may help in differentiating infants who will remain in NEC stage 1 from those who would progress to NEC stage 2 and 3 .

\section{MATERial AND METHOdS}

A retrospective chart review of 82 preterm infants less than 32 weeks GA from January 2002 to December 2008 was conducted at the Neonatal Intensive Care Unit at the Maimonides Medical Center. Infants with major congenital anomalies, congenital heart disease, and gastrointestinal disorders requiring surgery were excluded from the study. Those infants diagnosed as spontaneous intestinal perforation by pathology were also excluded from the study. This study was approved by the Institutional Review Board at Maimonides Medical Center.

Cases included 41 preterm infants that were diagnosed with NEC Stage 2 or 3, based on the modified Bell's staging criteria, defined as presence of pneumatosis intestinalis, portal venous gas or free air in abdomen, reported by a pediatric radiologist. ${ }^{[20]}$ Controls comprised of GA, weight and gender-matched preterm infants with feeding intolerance or suspected NEC but without pneumatosis intestinalis and/or portal venous gas.

The diagnostic parameters used for creating the predictive scoring tool to define NEC severity were chosen from common clinical symptoms and signs associated with suspicion of NEC ${ }^{[12-15,20-25]}$ and are summarized in Table 1. The scoring tool consisted of clinical presentation, radiological and laboratory findings, feeding characteristics and gastric residuals. Scores of 0,1 and 2 were given based on the severity of clinical presentation, abnormality of the laboratory values and xray findings. The individual scores for each characteristic included in the tool were summed to establish a final 
composite score. The scores were calculated at 12 hours, 24 hours, and 2 and 7 days prior to the time when NEC was first suspected. From these time points, the clinical course was then followed to evaluate for the development of pneu- matosis intestinalis, portal venous gas or free air in abdomen as determined by a pediatric radiologist, characteristics that defined cases (with these radiological signs) and controls (without radiological signs).

Table 1. NEC scoring system

\begin{tabular}{|c|c|c|c|}
\hline Score & $\mathbf{0}$ & 1 - one or more criteria present & 2 - one or more criteria present \\
\hline 1. Clinical & No clinical sign or symptoms & $\begin{array}{l}\text { 1. Apnea/bradycardia/ desaturation } \\
\text { 2. Temperature instability } \\
\text { 3. Lethargy/irritability } \\
\text { 4. Hypotension/decreased urine output } \\
\text { 5. Glucose instability } \\
\text { 6. Vomiting/abdominal distention/abdominal tenderness } \\
\text { 7. Guaiac-positive stool/bloody stool }\end{array}$ & $\begin{array}{l}\text { 1. Starting CPAP or mechanical } \\
\text { ventilation } \\
\text { 2. Change from CPAP to mechanical } \\
\text { ventilation } \\
\text { 3. Vasopressor support }\end{array}$ \\
\hline 2. Abdominal $X$-ray & Normal gas pattern & Mild or moderate distention of bowel loops & $\begin{array}{l}\text { 1. Focal thickening of bowel loops } \\
\text { 2. Fixed/persistent dilation of bowel } \\
\text { loops }\end{array}$ \\
\hline 3. Laboratory results & Normal laboratory values & $\begin{array}{l}\text { 1. WBC }<5 \text { or }>30 / \mu \mathrm{l} \\
\text { 2. Neutrophils }<1,000 / \mu \mathrm{l} \\
\text { 3. Platelets }<50,000 / \mu \mathrm{l} \\
\text { 4. Bands }>10 \% \\
\text { 5. IT ratio }>0.2 \\
\text { 6. Metabolic acidosis }-\mathrm{pH}<7.2 \text { or } \mathrm{HCO}_{3}<16 \\
\text { 7. } \mathrm{CRP}>1 \mathrm{mg} / \mathrm{dl}\end{array}$ & Positive blood culture \\
\hline $\begin{array}{l}\text { 4. Enteral Feeding: } \\
\text { type and rate of } \\
\text { advancement }\end{array}$ & $\begin{array}{l}\text { 1. Nil per os } \\
\text { 2. EBM with or without } \\
\text { fortification and advanced } \\
<20 \mathrm{ml} / \mathrm{kg} / \text { day }\end{array}$ & $\begin{array}{l}\text { 1. Formula or combination of EBM and formula } \\
\text { advanced at }<20 \mathrm{ml} / \mathrm{kg} / \text { day }\end{array}$ & $\begin{array}{l}\text { 1. Formula or EBM or combination } \\
\text { of EBM and formula advanced at } \\
\geq 20 \mathrm{ml} / \mathrm{kg} / \text { day }\end{array}$ \\
\hline $\begin{array}{l}\text { 5. Gastric residuals: } \\
\text { type and volume }\end{array}$ & $\begin{array}{l}\text { 1. No gastric residuals } \\
\text { 2. Pregavage residuals: clear or } \\
\text { partially digested or undigested } \\
\text { milk }<30 \% \text { of total amount of } \\
\text { prior enteral feed }\end{array}$ & $\begin{array}{l}\text { 1. Pregavage residuals characterized as bilious or bloody } \\
<30 \% \text { of total amount of enteral feeding given in prior } \\
\text { feed } \\
\text { 2. Pregavage residuals characterized as clear or partially } \\
\text { digested or undigested milk } \geq 30 \% \text { of total amount of } \\
\text { enteral feeding given in prior feed }\end{array}$ & $\begin{array}{l}\text { 1. Pregavage residuals characterized } \\
\text { as bilious or bloody } \geq 30 \% \text { of total } \\
\text { amount of enteral feeding given in } \\
\text { prior feed }\end{array}$ \\
\hline
\end{tabular}

Note. EBM: Expressed breast milk; WBC: White blood cell; IT: immature to mature neutrophil; CRP: C-reactive protein; CPAP: continuous positive airway pressure

Data were extracted from the patients' medical records by authors (Grino, Miller and Carasquilla-Lopez) and was confirmed to have $92 \%$ consistency when independent review was performed by a different author (Rastogi). Demographic and clinical data including antenatal and postnatal characteristics of the cases and controls was also abstracted to study if there were any other characteristics that might influence the outcomes of interest.

\section{Statistical analysis}

The components of the scoring tool and the composite scores were compared between the cases and controls using Student $\mathrm{T}$ test for continuous variables and the chi-square analysis for categorical variables. The differences in the composite score to study prediction of infants who develop NEC stage 2 or 3 from controls were studied using repeated measures analysis as different time intervals. Sensitivity, specificity and area under curve were calculated for various scores and at 4 times points of the study.

\section{RESUlts}

Based on the selection criteria, baseline GA, birth weight and demographic information did not differ between the cases and controls (see Table 2). Among the cases, $26(63.4 \%)$ had stage 2 and $15(36.6 \%)$ had stage 3 NEC. There were also no differences in antenatal and postnatal factors, and neonatal comorbidities between the cases and controls. Surgical intervention was required in 14 (34.1\%) cases and none among controls. More cases were intubated as compared to controls ( $p<.01$, see Table 3 ). The median length of hospital stay for cases was longer 70 days (range 10-208 days) as compared to 65 days (range 17-161 days) in the controls $(p<.05)$. Mortality was also higher among the cases; 12 cases $(29.3 \%)$ died as compared to 2 controls (5\%) $(p<.01)$. 
Table 2. Demographic characteristics of the study subjects

\begin{tabular}{llll}
\hline Demographic characteristic & Control $(\mathbf{n}=\mathbf{4 1})$ & NEC $(\mathbf{n}=\mathbf{4 1})$ & $\boldsymbol{p}$-value \\
\hline Male n (\%) & $22(55.0)$ & $29(70.7)$ & .11 \\
Mean Gestational Age in weeks (SD) & $27.8(2.10)$ & $27.8(2.10)$ & .97 \\
Mean Birth Weight in grams (SD) & $1,116.4(309.0)$ & $1,114.05(363.6)$ & .98 \\
Ethnicity (within race) n (\%) & & & .44 \\
- White Non-Hispanic & $16(40.0)$ & $13(31.7)$ & \\
- Black Non-Hispanic & $5(15.0)$ & $9(19.5)$ & \\
- Hispanic & $11(27.5)$ & $8(24.4)$ & \\
- Asian & $5(12.5)$ & $9(22.0)$ & .13 \\
Mean Postmenstrual age at diagnosis in weeks (SD) & $31.08(2.0)$ & $32.1(3.0)$ & .95 \\
Multiple births n (\%) & $11(27.5)$ & $11(26.8)$ & .20 \\
Mean Weight at diagnosis in grams (SD) & $1,375.7(538.4)$ & $1,542.14(577.9)$ & .2 \\
Median age in days at diagnosis (min, max) & $21(3,92)$ & $26(6,76)$ & \\
\hline
\end{tabular}

Note. NEC: necrotizing enterocolitis

Table 3. Clinical characteristics of the study subjects $(\mathrm{N}=41)$

\begin{tabular}{llll}
\hline Clinical characteristics & Control n(\%) & NEC n(\%) & p-value \\
\hline Prenatal steroids & $35(87.5)$ & $35(85.4)$ & .78 \\
Preeclampsia & $7(17.5)$ & $5(12.2)$ & .5 \\
Maternal diabetes/Gestational diabetes & $3(7.5)$ & $2(4.9)$ & .62 \\
Chorioamnionitis & $3(7.5)$ & $2(4.9)$ & .62 \\
Small for gestational age & 0 & $4(9.8)$ & .11 \\
Intubation - anytime before diagnosis & $19(47.5)$ & $33(80.5)$ & .002 \\
Surfactant & $13(32.5)$ & $13(31.7)$ & .94 \\
Anemia & $36(90)$ & $37(90.2)$ & .97 \\
Caffeine & $20(50)$ & $24(60)$ & .37 \\
Postnatal steroids & $4(10)$ & $10(24.4)$ & .09 \\
Gastro-esophageal reflux & $5(12.5)$ & $6(14.6)$ & .78 \\
Broncho-pulmonary disease & $4(10)$ & $8(19.5)$ & .23 \\
Patent ductus arteriosus & $40(10)$ & $28(68.3)$ & .32 \\
Intra ventricular hemorrhage III-IV & $2(5)$ & $1(2.4)$ & .54 \\
Surgical treatment & 0 & $14(34.1)$ & .001 \\
Death & $2(5)$ & $12(29.3)$ & .004 \\
Median length of stay in days (min, max) & $63(17,125)$ & $93(23,173)$ & .01 \\
\hline
\end{tabular}

Note. NEC: necrotizing enterocolitis

The relationship between the clinical, radiological, laboratory, feeding characteristic and gastric residuals scores, along with the composite score (see Table 4). The composite scores were significantly higher among cases than controls at day 7 $(p<.01), 24$ hours $(p<.05)$, and 12 hours $(p<.001)$ before the time when NEC was suspected (see Figure 1). The score was most influenced by the presence of increased incidence of abnormal laboratory findings $(p<.05)$ and feeding characteristics $(p<.001)$ and gastric residuals $(p<.05)$ at 12 hours prior to diagnosis. The 24 hour before the suspicion of NEC was clinically relevant as scores from this point would be able to predict infants who were at risk to progress to NEC stage 2 or 3 , hence aggressive treatment instituted at the time of suspicion itself might prevent or ameliorate the worsening of the disease process and its associated complications.

Sensitivity, specificity and area under curve (see Table 5) at the score of $\leq 2$ best discriminated between stage 1 NEC with Stage 2 and 3 NEC at various time points specially 24 and 12 hours before the diagnosis of NEC was made.

\section{Discussion}

A timely diagnosis of NEC is important because of its unpredictable course that can rapidly progress in severity and is associated with high mortality and morbidity. We report a scoring tool developed using a combination of clinical, respiratory, gastrointestinal, radiological and laboratory findings which can help predict severity of NEC as early as 24 
hours prior to when NEC is suspected and intervention at this point may prevent disease progression to sever disease. As compared to other scoring tools that predict the risk of developing NEC, this scoring tool allows early prediction of NEC severity, identifying infants that may develop NEC stages 2 and 3 as compared to those that will stay at NEC stage 1 or may have conditions that mimic NEC. This early differentiation may help us to aggressively treat babies who are at risk for developing stage 2 or 3 and thereby decrease mortality and morbidity associated with NEC stage 2 and 3. It could also prevent indiscriminate use of antibiotics, which might itself be associated with adverse outcomes.

Table 4. Details of individual and composite scores among controls and infants with NEC

\begin{tabular}{|c|c|c|c|c|}
\hline Components of the score & Time prior to diagnosis & Controls (Mean $\pm S D$ ) & NEC $($ Mean $\pm S D)$ & $p$-value \\
\hline \multirow{4}{*}{ Clinical } & D7 & $1.48 \pm 0.12$ & $1.61 \pm 0.12$ & .44 \\
\hline & D2 & $1.58 \pm 0.12$ & $1.56 \pm 0.12$ & .93 \\
\hline & D1 & $1.58 \pm 0.11$ & $1.61 \pm 0.11$ & .82 \\
\hline & D0.5 & $1.58 \pm 0.10$ & $1.76 \pm 0.10$ & .47 \\
\hline \multirow{4}{*}{ Radiology } & D7 & $0.00 \pm 0.02$ & $0.02 \pm 0.02$ & .33 \\
\hline & D2 & 0.00 & 0.00 & --- \\
\hline & D1 & $0.05 \pm 0.05$ & $0.10 \pm 0.05$ & .54 \\
\hline & D0.5 & $0.43 \pm 0.11$ & $0.32 \pm 0.11$ & 4.78 \\
\hline \multirow{4}{*}{ Laboratory } & D7 & $0.01 \pm 0.06$ & $0.20 \pm 0.06$ & .02 \\
\hline & $\mathrm{D} 2$ & $0.03 \pm 0.05$ & $0.17 \pm 0.05$ & .03 \\
\hline & D1 & $0.01 \pm 0.04$ & $0.12 \pm 0.04$ & .05 \\
\hline & D0.5 & $0.10 \pm 0.08$ & $0.34 \pm 0.08$ & .05 \\
\hline \multirow{4}{*}{ Feeding } & D7 & $0.20 \pm 0.07$ & $0.41 \pm 0.07$ & .04 \\
\hline & D2 & $0.28 \pm 0.08$ & $0.56 \pm 0.08$ & .13 \\
\hline & D1 & $0.28 \pm 0.09$ & $0.68 \pm 0.08$ & .001 \\
\hline & D0.5 & $0.18 \pm 0.11$ & $1.24 \pm 0.11$ & .001 \\
\hline \multirow{4}{*}{ Gastric Residuals } & D7 & $0.20 \pm 0.08$ & $0.32 \pm 0.08$ & .29 \\
\hline & D2 & $0.07 \pm 0.07$ & $0.307 \pm 0.07$ & .03 \\
\hline & D1 & $0.30 \pm 0.09$ & $0.22 \pm 0.09$ & .51 \\
\hline & D0.5 & $0.23 \pm 0.11$ & $0.54 \pm 0.10$ & .04 \\
\hline \multirow{4}{*}{ Grand total } & D7 & $1.93 \pm 0.18$ & $2.56 \pm 0.18$ & .01 \\
\hline & D2 & $2.18 \pm 0.17$ & $2.37 \pm 0.17$ & .42 \\
\hline & D1 & $2.20 \pm 0.20$ & $2.73 \pm 0.20$ & .05 \\
\hline & D0.5 & $2.50 \pm 0.22$ & $4.20 \pm 0.22$ & .001 \\
\hline
\end{tabular}

Note. $\mathrm{D} 7$ = Day 7 before the diagnosis; D2 = Day 2 before the diagnosis; D1 = Day 1 before the diagnosis; D0.5 = Day 0.5 before the diagnosis; NEC: necrotizing enterocolitis
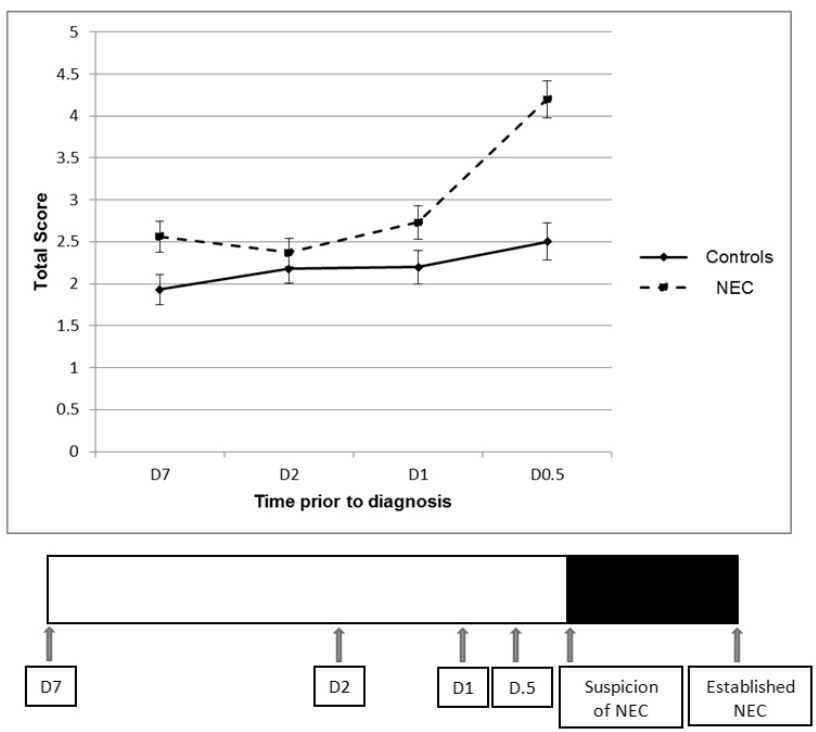

Figure 1. Composite total scores of the prediction tool in infants with NEC Stage 2 and 3, and controls at day 7 (D7), day 2 (D2), 24 hours (D1) and 12 hours (D0.5) before the suspicion of NEC
Studies which have used single clinical or laboratory measure to predict the development of NEC have not been shown to be sensitive or specific due to the protean presentations of NEC. Similarly, a common presentation, such as apnea/bradycardia episodes, presence of bands in peripheral blood counts, bloody stools, or acidosis in established NEC have been inconclusive since these findings have been inconsistently present in NEC and present in other illness. ${ }^{[20-25]}$ Since the manifestations of NEC are varied, and may affect respiratory, immune, or gastrointestinal systems, using a scoring tool that includes all these presentations may improve the prediction, particularly among the infants who would develop NEC stage 2 or 3.

Recently, Ji et al. ${ }^{[26]}$ devised a computer-based algorithm utilizing demographic, clinical, radiological, laboratory and feeding parameters to develop a risk stratification model in an attempt to predict disease severity at the presentation of NEC. Clinical features such as respiratory distress and gastric residuals, observed to be different between the 2 study groups in our study, and in prior reports ${ }^{[13]}$ were not observed 
to be significant by Ji et al. ${ }^{[26]}$ This lack of association between respiratory distress and gastric residuals and severity of NEC observed by Ji et al. could be related to inclusion of multiple factors in their study that may be collinear relationship to these clinical measures, and may explain the loss of statistical significance in multivariate analysis. Further, there is difference in the timing when the scores were performed. In our study, the score was calculated at several time points prior to initial suspicion of NEC while for Ji et al. it was when the disease was already established. This difference has substantial clinical importance since the elucidation of at risk prior to disease onset and progression will allow initiation of aggressive treatment as compared to continued clinical observation. More recently Fox et al. ${ }^{[19]}$ developed a scoring tool used to predict progression to NEC stage 1 with early intervention leading to stopping the progression of NEC stage 1 to NEC stage 2 and stage 3 . The parameters used were readily available clinical data, including behavioral, cardiovascular, respiratory and gastrointestinal parameters, but lacked inclusion of routine laboratory data which are included in our tool and infact they are the more discriminatory of the studied parameters between NEC stage 1 and NEC stage 2 and 3.

Table 5. Area under the curve, sensitivity and specificity for scores of $<2$ at specific time points before the diagnosis of necrotizing enterocolitis

\begin{tabular}{cllll}
\hline Time before NEC in days & AUC \pm SE & 95\% CI & Sensitivity & Specificity \\
\hline 0.5 & $0.80 \pm 0.05$ & $0.70-0.90$ & 0.98 & 0.83 \\
1 & $0.62 \pm 0.06$ & $0.50-0.75$ & 0.85 & 0.75 \\
2 & $0.53 \pm 0.06$ & $0.41-0.66$ & 0.85 & 0.78 \\
7 & $0.64 \pm 0.06$ & $0.52-0.76$ & 0.85 & 0.72 \\
\hline
\end{tabular}

Note. NEC: necrotizing enterocolitis; AUC: area under the curve; CI: confidence interval

Early prediction of severity of NEC gives clinicians opportunity to use biomarkers to confirm diagnosis, and institute newer and novel treatment modalities which may not only decrease the severity of NEC but may be able to completely prevent it as there is a time lag between the prediction tool and the established disease. Also as these newer modalities are expensive, the ability to define a population which may be at risk for developing severe disease, these diagnostic and treatment modalities can be used judiciously for at risk population. ${ }^{[27-30]}$

Our findings are limited by the retrospective nature of our study, although we validated the data extraction from charts, variation in nursing documentation of clinical signs may have altered our findings. Use of this multi-parameter scoring tool to determine whether more aggressive treatment for at risk infants for developing NEC stage 2 and 3, even before radiological confirmation of pneumatosis intestinalis, may result in a less severe course of NEC and improve morbidity and mortality.

In conclusion, we describe a multi-parameter scoring tool that includes routinely available clinical, radiological, laboratory and feeding variables and is able to distinguish infants who will develop NEC stage 2 and 3 from those with NEC stage 1, 24 hours prior to established disease. Since this a pilot study further investigation aimed at prospectively validating this screening tool is needed.

\section{ACKNOWLEDGEMENTS}

Authors would like to acknowledge Susan Grossman, MPA, and Eleanor Stoner, RN for supporting this research project, and Raychel Ryan, RN, Aimee Garcia, RN, and Rebecca Manatad, $\mathrm{RN}$ for contributing in the review of patient charts.

\section{CONFlicts of Interest Disclosure}

The authors have no conflict of interest related to this article.

\section{REFERENCES}

[1] Lin PW, Stoll BJ. Necrotizing enterocolitis. Lancet. 2006; 368: 1271-1283. http://dx.doi.org/10.1016/S0140-6736(06)6 9525-1

[2] Gregory KE. Clinical predictors of necrotizing enterocolitis in preterm infants. Nursing Research. 2008; 57(4): 260-270. PMid: 18641495. http://dx.doi.org/10.1097/01.NNR.0000 313488.72035.a9

[3] Hunter CJ, Podd B, Ford HR, et al. Evidence vs. experience in neona- tal practices in necrotizing enterocolitis. J Perinatol. 2008; 28: S9S13. PMid: 18446181. http://dx.doi.org/10.1038/jp. 2008 .43

[4] Blakely ML, Lally KP, McDonald S, et al. Postoperative outcomes of extremely low birth weight infants with necrotizing enterocolitis or isolated intestinal perforation: a prospective cohort study by the NICHD Neonatal Research Network. Annals of Surgery. 2005; 24: 984-994. http://dx.doi.org/10.1097/01.sla.00001641 $81.67862 .7 f$ 
[5] Lin PW, Nasr TR, Stoll BJ. Necrotizing enterocolitis: Recent scientific advances in pathophysiology and prevention. Sem Perinatol. 2008; 32: 70-82. PMid: 18346530. http://dx.doi.org/10.10 53/j.semperi.2008.01.004

[6] Schulze SM, Deshpande GC, Patole SK. Neurodevelopmental outcomes of very low- birth-weight infants with necrotizing enterocolitis. Arch Pediatr Adol Med. 2007; 161: 583-590. PMid: 17548764. http://dx.doi.org/10.1001/archpedi.161.6.583

[7] Young C, Sharma R, Handfield M, et al. Biomarkers for infants at risk for necrotizing enterocolitis: Clues to prevention? Pediatr Res. 2009; 65: 91R-97R. PMid: 19190533. http://dx.doi.org/10. 1203/PDR. Ob013e31819dba7d

[8] Evennett N, Alexander N, Petrov M, et al. A toolatic review of serologic tests in the diagnosis of necrotizing enterocolitis. $\mathrm{J} \mathrm{Pe}-$ diatr Surg. 2009; 44(11): 2192-2201. PMid: 19944232. http: //dx.doi.org/10.1016/j.jpedsurg.2009.07.028

[9] Sylvester KG, Ling XB, Liu GY, et al. Urine protein biomarkers for the diagnosis and prognosis of necrotizing enterocolitis in infants. J Pediatr. 2014;164(3): 607-612. PMid: 24433829. http: //dx.doi.org/10.1016/j.jpeds.2013.10.091

[10] Ng PC. Biomarkers of necrotizing enterocolitis. Sem in Fetal and Neonatal Med. 2014;19: 33-38. PMid: 24080072. http://dx.doi .org/10.1016/j.siny.2013.09.002

[11] Benkoe T, Reck C, Gleiss A, et al. Interleukin 8 correlates with intestinal involvement in surgically treated infants with necrotizing enterocolitis. J Pediatr Surg. 2012; 47(8): 1548-54. PMid: 22901915. http://dx.doi.org/10.1016/j.jpedsurg.2011.11.049

[12] Gephart SM, Spitzer AR, Effken JA, et al. Discrimination of GutCheck(NEC): a clinical risk index for necrotizing enterocolitis. J Perinatol. 2014; 34: 468-75. PMid: 24651734. http://dx.d oi.org/10.1038/jp. 2014.37

[13] Gregory KE, DeForge CE, Natale KM, et al. Necrotizing enterocolitis in the preterm infant. Adv in Neonatal Care. 2011; 11(3): 155-164. PMid: 21730907. http://dx.doi.org/10.1097/ANC.0b013e3 1821 baaf 4

[14] Moss RL, Kalish LA, Duggan C, et al. Clinical parameters do not adequately predict outcome in necrotizing enterocolitis: a multiinstitutional study. J Perinatol. 2008; 28: 665-674. PMid: 18784730. http://dx.doi.org/10.1038/jp. 2008.119

[15] McKeown RE, March TD, Garrison CZ, et al. The prognostic value of a risk score for necrotizing enterocolitis. Paediatr Perinatal Epidemiol. 1994; 8: 156-165. http://dx.doi.org/10.1111/j.136 5-3016.1994.tb00446.x

[16] Saari A, Virta LJ, Sankilampi U, et al. Antibiotic exposure in infancy and risk of being overweight in the first 24 months of life. Pediatr. 2015; 135(4): 617-26. PMid: 25825533. http://dx.doi.org/10. 1542/peds . 2014-3407

[17] Arboleya S, Sánchez B, Milani C, et al. Intestinal microbiota development in preterm infants and effect of perinatal antibiotics. J Pediatr. 2015; 166(3): 538-44. PMid: 25444008. http://dx . doi.org/10. $1016 / j \cdot j$ peds . 2014.09 .041
[18] Sho S, Neal MD, Sperry J, et al. A novel scoring system to predict the development of necrotizing enterocolitis totalis in premature infants. J Pediatr Surg. 2014; 49(7): 1053-6. PMid: 24952787. http://dx.doi.org/10.1016/j.jpedsurg.2013.10.023

[19] Fox JR, Thacker LR, Hendricks-Mu-oz KD. Early Detection Tool of Intestinal Dysfunction: Impact on Necrotizing Enterocolitis Severity. Am J Perinatol. 2015; 32(10): 927-32. PMid: 25799177. http://dx.doi.org/10.1055/s-0034-1543984

[20] Bell M, Ternberg J, Feigin R, et al. Neonatal necrotizing enterocolitis: therapeutic decisions based upon clinical staging. Ann Surg. 1978; 187: 1-7. PMid: 413500. http://dx.doi.org/10.1097/00000 658-197801000-00001

[21] Bertino E, Giuliani F, Prandi G, et al. Necrotizing enterocolitis: risk factor analysis and role of gastric residuals in very low birth weight infants. J Pediatr Gastroenterol Nutr. 2009; 48(4): 437-42. PMid: 19330932. http://dx.doi.org/10.1097/MPG.0b013e3 $1817 \mathrm{~b} 6 \mathrm{dbe}$

[22] Christenson RD, Wiedmeier SE, Baer VL, et al. Antecedents of Bell stage III necrotizing enterocolitis. J of Perinatol. 2010; 30: 54-57. PMid: 19609307. http://dx.doi.org/10.1038/jp.2009.93

[23] Cobb BA, Carlo WA, Ambalavanan N. Gastric residuals and their relationship to necrotizing enterocolitis in very low birth weight infants. Pediatr. 2004; 113: 50-3. http://dx.doi.org/10.1542/p eds.113.1.50

[24] Daneman A, Woodward S, de Silva M. The radiology of necrotizing enterocolitis: A review of 47 cases and the literature. Ped Radiol. 1978; 7: 70-77. http://dx.doi.org/10.1007/BF00975674

[25] Thompson A, Bizzarro M, Yu S, et al. Risk factors for necrotizing enterocolitis totalis: a case-control study. J Perinatol. 2011; 31(11): 730-8. PMid: 21436786. http://dx.doi.org/10.1038/jp. 20 11.18

[26] Ji J, Ling XB, Zhao Y, et al. A data-driven algorithm integrating clinical and laboratory features for the diagnosis and prognosis of necrotizing enterocolitis. PLOS One. 2014; 2: e89860. PMid: 24587080. http://dx.doi.org/10.1371/journal .pone.0089860

[27] Karadag A, Ozdemir R, Kurt A, et al. Protective effects of dexpanthenol in an experimental model of necrotizing enterocolitis. J Pediatr Surg. 2015; 50(7): 1119-24. PMid: 25783305. http: //dx.doi.org/10.1016/j.jpedsurg.2014.10.053

[28] Ozdemir R, Yurttutan S, Sari FN, et al. All-trans-retinoic acid attenuates intestinal injury in a neonatal rat model of necrotizing enterocolitis. Neonatology. 2013; 104(1): 22-7. PMid: 23615357. http://dx.doi.org/10.1159/000350510

[29] Ozdemir R, Yurttutan S, Sarı FN, et al. Antioxidant effects of $\mathrm{N}$-acetylcysteine in a neonatal rat model of necrotizing enterocolitis. J Pediatr Surg. 2012; 47(9): 1652-7. PMid: 22974601. http://dx.doi.org/10.1016/j.jpedsurg.2012.02.016

[30] Guven A, Gundogdu G, Uysal B, et al. Hyperbaric oxygen therapy reduces the severity of necrotizing enterocolitis in a neonatal rat model. J Pediatr Surg. 2009; 44(3): 534-40. PMid: 19302854. http://dx.doi.org/10.1016/j.jpedsurg.2008.06.008 